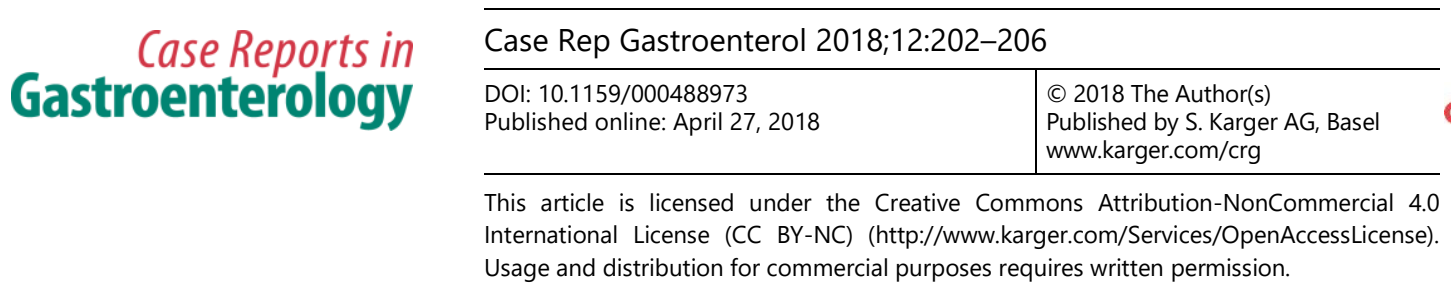

\title{
Multidetector-Row Computed Tomography and Colonoscopy for Detecting a Rectal Dieulafoy Lesion as a Source of Lower Gastrointestinal Hemorrhage
}

\author{
Manabu Kaneko ${ }^{a}$ Hiroaki Nozawa $^{a}$ Yosuke Tsuji ${ }^{b}$ Shigenobu Emoto ${ }^{a}$ \\ Koji Murono ${ }^{a}$ Takeshi Nishikawa $^{a}$ Kazuhito Sasaki ${ }^{a}$ Kensuke Otani ${ }^{a}$ \\ Toshiaki Tanaka $^{a}$ Keisuke Hata $^{a} \quad K^{2}$ Kazushige Kawai ${ }^{a}$ Kazuhiko Koike ${ }^{b}$ \\ ${ }^{a}$ Department of Surgical Oncology, University of Tokyo, Tokyo, Japan; b Department of \\ Gastroenterology, University of Tokyo, Tokyo, Japan
}

\section{Keywords}

Dieulafoy lesion $\cdot$ Hemorrhage $\cdot$ Endoscopic hemostasis

\begin{abstract}
A Dieulafoy lesion of the rectum is a very rare entity that can cause massive lower gastrointestinal (Gl) hemorrhage. Identifying the bleeding point is sometimes difficult because these lesions are very small. We herein describe an 82-year-old man with active hemorrhage due to a rectal Dieulafoy lesion. He was referred to our hospital because of persistent hematochezia from the morning of that day. He had a history of atrial fibrillation, chronic heart failure, diabetes mellitus, and hyperuricemia. Prompt multidetector-row computed tomography (MDCT) enabled us to detect active bleeding from the lower rectum. Subsequently, colonoscopy revealed an exposed vessel in the lower rectum without surrounding ulceration, and hemostasis was successfully achieved using a hemostatic forceps with soft coagulation. After hemostasis had been achieved, the patient recovered and was discharged without complications and rebleeding. He is doing well 6 months after discharge from the hospital. Sequential ex-
\end{abstract}




\section{Case Reports in Gastroenterology}

Case Rep Gastroenterol 2018;12:202-206 DOI: $10.1159 / 000488973$ (c) 2018 www.karger.com/crg

Kaneko et al.: Efficient Treatment Strategy for a Rectal Dieulafoy Lesion

amination by MDCT and colonoscopy is considered an efficient treatment strategy for patients with active lower GI bleeding.

(C) 2018 The Author(s)

Published by S. Karger AG, Basel

\section{Introduction}

Acute gastrointestinal (GI) bleeding is a potentially lethal condition that usually leads to hospital admission. It is caused by peptic ulcers and esophageal or gastroduodenal erosions in almost $80 \%$ of patients [1]. Lower GI bleeding is diagnosed in $20-30 \%$ of all patients with GI bleeding [2]. The annual incidence of lower GI bleeding is approximately $0.03 \%$, and it is associated with older age and preexisting comorbidities [2]. The Dieulafoy lesion was named after the French surgeon Georges Dieulafoy, who characterized it in 1898 [3]. Although Dieulafoy lesions are believed to account for only 1-2\% of cases of acute GI bleeding, it is difficult to accurately determine their true incidence since they are nonsymptomatic until the commencement of bleeding and are too small to locate [1]. We herein describe the case of an 82year-old man with a rectal Dieulafoy lesion who presented with active and persistent lower GI bleeding. The diagnosis was made based on multidetector-row computed tomography (MDCT), and endoscopic hemostasis was successfully achieved.

\section{Case Report}

An 82-year-old male patient was referred to our hospital because of persistent hematochezia for approximately half a day. He had a history of atrial fibrillation, chronic heart failure, diabetes mellitus, and hyperuricemia. He had been receiving antiplatelet therapy for several years. He had no history of upper GI symptoms or nonsteroidal anti-inflammatory agent use. On arrival, his blood pressure was 118/56 mm $\mathrm{Hg}$ and his heart rate was 83 beats/min. Laboratory tests results revealed that the hemoglobin level was $8.3 \mathrm{~g} / \mathrm{dL}$ (reference range 11.6-14.8 g/dL), the hematocrit level was $25.3 \%$ (reference range $35.1-44.4 \%$ ), the platelet count was $11.7 \times 10^{4} / \mu \mathrm{L}$ (reference range $15.8-34.8 \times 10^{4} / \mu \mathrm{L}$ ), and coagulation parameters were normal. His abdomen was soft and flat, without tenderness or rebound tenderness. Digital rectal examination revealed no mass, except for a dark-red blood clot and the presence of fresh blood. At the time, the source of bleeding was unknown. To identify the site of bleeding, prompt MDCT was performed, and the scan clearly showed active contrast extravasation in the lower rectum (Fig. 1). Subsequently, urgent colonoscopy was performed with bowel preparation, and pulsatile, fresh bleeding from the exposed nipple-like vessel was observed without mucosal defect or ulceration in the lower rectum (Fig. 2). The morphology of the lesion was consistent with a Dieulafoy lesion. Endoscopic hemostasis was achieved quickly using a pair of hemostatic forceps with soft coagulation at $60 \mathrm{~W}$. The patient's systolic blood pressure decreased to $80 \mathrm{~mm}$ Hg during colonoscopy, and he needed blood transfusion. He received six units of red blood cells during his hospital stay.

After hemostasis had been achieved, the patient recovered and was discharged without recurrence of bleeding or other complications. He is doing well 6 months after hospital discharge. 


\section{Discussion}

Acute lower GI bleeding has an incidence of approximately 36 cases per 100,000 per year [4]. The most common causes are diverticular disease, colonic angiodysplasia, ischemic colitis, hemorrhoids, and colorectal polyps/neoplasms, accounting for more than $95 \%$ of cases [5]. The Dieulafoy lesion is a very rare cause of acute lower GI bleeding. It is characterized by a small mucosal defect in otherwise healthy mucosa containing a single protruding vessel, and it is most frequently observed in the stomach (70\%), less commonly in the duodenum (15\%), and rarely in the lower GI tract, including the rectum [3].

Although most patients with acute lower GI bleeding stop bleeding spontaneously and have favorable outcomes, morbidity and mortality are increased in older patients and those with comorbid medical conditions [6]. In most cases, the patients with a Dieulafoy lesion are aged and have multiple comorbidities, such as cardiopulmonary dysfunction and chronic renal insufficiency, with a history of recurrent use of nonsteroidal anti-inflammatory drugs (e.g., acetylsalicylic acid) and warfarin [7, 8]. These reported clinical characteristics of patients with a Dieulafoy lesion applied to our patient.

Colonoscopy is the gold standard in diagnosing acute lower GI bleeding [1, 2]. Estimates for the diagnostic yield in recent studies range from 42 to $100 \%$ [9]. The procedures include an epinephrine solution injection, thermal contact coagulation, argon plasma coagulation, hemostatic clips, and band ligation [2]. When endoscopy is used to successfully detect a Dieulafoy lesion, endoscopic treatment is achieved in $90 \%$ of patients with this lesion [10, 11]. However, the endoscopic procedure is not always successful, and repeat examinations are needed to make the diagnosis in some patients because the lesion is very small and blood, hematoma, or feces in the intestinal lumen prevent endoscopic visibility of the bleeding site. In such patients, there is a possibility that MDCT could be useful in the diagnosis [12, 13]. Computed tomography is noninvasive and can be used to detect active colonic hemorrhage at a lower rate $(0.3 \mathrm{~mL} / \mathrm{min})$ compared with angiography $(0.5 \mathrm{~mL} / \mathrm{min})$ [14]. In our patient, prompt MDCT enabled us to locate the bleeding site, and thus sequential endoscopic hemostasis was achieved quickly. Considering the outcome of our patient, we suggest MDCT as a useful tool to narrow down the location of lower GI bleeding.

In conclusion, detection of the bleeding site using MDCT followed by colonoscopic hemostasis is an efficient treatment strategy in patients with bleeding from a rectal Dieulafoy lesion. More studies are needed in the future to evaluate the potential use of such a strategy in the management of patients with lower GI bleeding.

\section{Statement of Ethics}

Written informed consent for publication was obtained from the patient.

\section{Disclosure Statement}

The authors declare that there is no conflict of interest regarding the publication of this paper. 
Kaneko et al.: Efficient Treatment Strategy for a Rectal Dieulafoy Lesion

\section{References}

1 British Society of Gastroenterology Endoscopy Committee. Non-variceal upper gastrointestinal haemorrhage: guidelines. Gut. 2002 Oct;51 Suppl 4:iv1-6.

2 ASGE Standards of Practice Committee, Pasha SF, Shergill A, Acosta RD, Chandrasekhara V, Chathadi KV, Early D, Evans JA, Fisher D, Fonkalsrud L, Hwang JH, Khashab MA, Lightdale JR, Muthusamy VR, Saltzman JR, Cash BD. The role of endoscopy in the patient with lower GI bleeding. Gastrointest Endosc. 2014;79:875-85.

3 Baxter M, Aly EH. Dieulafoy's lesion: current trends in diagnosis and management. Ann R Coll Surg Engl. 2010 Oct;92(7):548-54.

4 Laine L, Yang H, Chang SC, Datto C. Trends for incidence of hospitalization and death due to GI complications in the United States from 2001 to 2009. Am J Gastroenterol. 2012 Aug;107(8):1190-5.

5 Harrison JD, Calatayud A, Thava VR, Kirby RM. Massive arterial bleeding from a single rectal vessel. Postgrad Med J. 1997 May;73(859):303-4.

6 Strate LL, Ayanian JZ, Kotler G, Syngal S. Risk factors for mortality in lower intestinal bleeding. Clin Gastroenterol Hepatol. 2008 Sep;6(9):1004-10.

7 Chaer RA, Helton WS. Dieulafoy's disease. J Am Coll Surg. 2003 Feb;196(2):290-6.

8 Lee YT, Walmsley RS, Leong RW, Sung JJ. Dieulafoy's lesion. Gastrointest Endosc. 2003 Aug;58(2):236-43.

9 Moss AJ, Tuffaha H, Malik A. Lower GI bleeding: a review of current management, controversies and advances. Int J Colorectal Dis. 2016 Feb;31(2):175-88.

10 Chung IK, Kim EJ, Lee MS, Kim HS, Park SH, Lee MH et al. Bleeding Dieulafoy's lesions and the choice of endoscopic method: comparing the hemostatic efficacy of mechanical and injection methods. Gastrointest Endosc. 2000 Dec;52(6):721-4.

11 Marangoni G, Cresswell AB, Faraj W, Shaikh H, Bowles MJ. An uncommon cause of life-threatening gastrointestinal bleeding: 2 synchronous Dieulafoy lesions. J Pediatr Surg. 2009 Feb;44(2):441-3.

12 Scheffel H, Pfammatter T, Wildi S, Bauerfeind P, Marincek B, Alkadhi H. Acute gastrointestinal bleeding: detection of source and etiology with multi-detector-row CT. Eur Radiol. 2007 Jun;17(6):1555-65.

13 Chen YY, Yen HH. Massive bleeding from a rectal Dieulafoy lesion: combined multidetector-row CT diagnosis and endoscopic therapy. Surg Laparosc Endosc Percutan Tech. 2008 Aug;18(4):398-9.

14 Eisen GM, Dominitz JA, Faigel DO, Goldstein JL, Kalloo AN, Petersen BT et al.; American Society for Gastrointestinal Endoscopy. Standards of Practice Committee. An annotated algorithmic approach to acute lower gastrointestinal bleeding. Gastrointest Endosc. 2001 Jun;53(7):859-63.

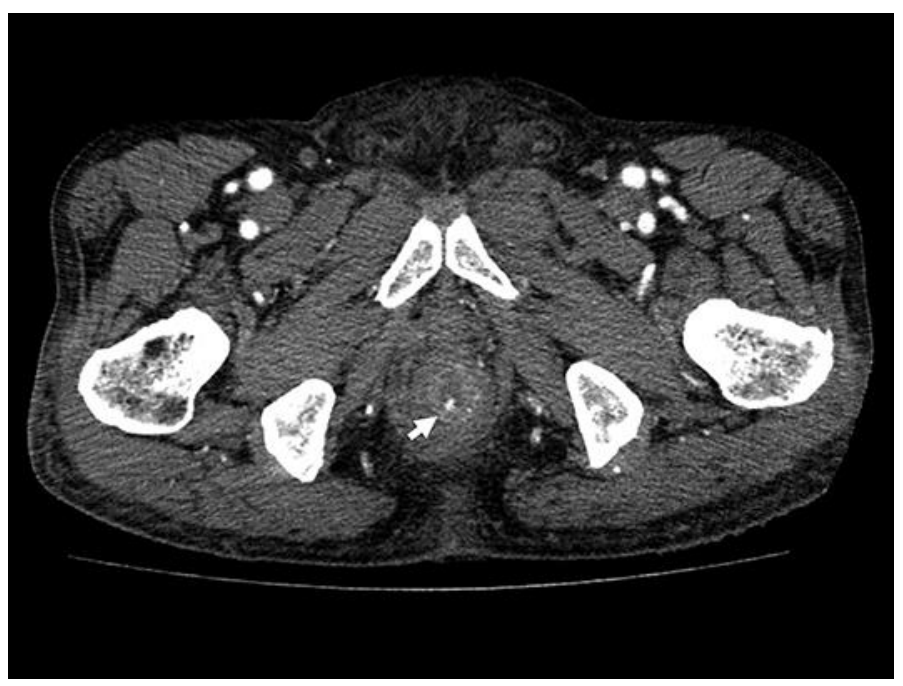

Fig. 1. Multidetector-row computed tomography scan clearly showing active contrast extravasation in the lower rectum (arrow). 


\begin{tabular}{|c|c|c|}
\hline \multirow{2}{*}{$\begin{array}{r}\text { Case Reports in } \\
\text { Gastroenterology }\end{array}$} & \multicolumn{2}{|c|}{ Case Rep Gastroenterol 2018;12:202-206 } \\
\hline & DOI: $10.1159 / 000488973$ & $\begin{array}{l}\text { (c) } 2018 \text { The Author(s). Published by S. Karger AG, Basel } \\
\text { www.karger.com/crg }\end{array}$ \\
\hline
\end{tabular}

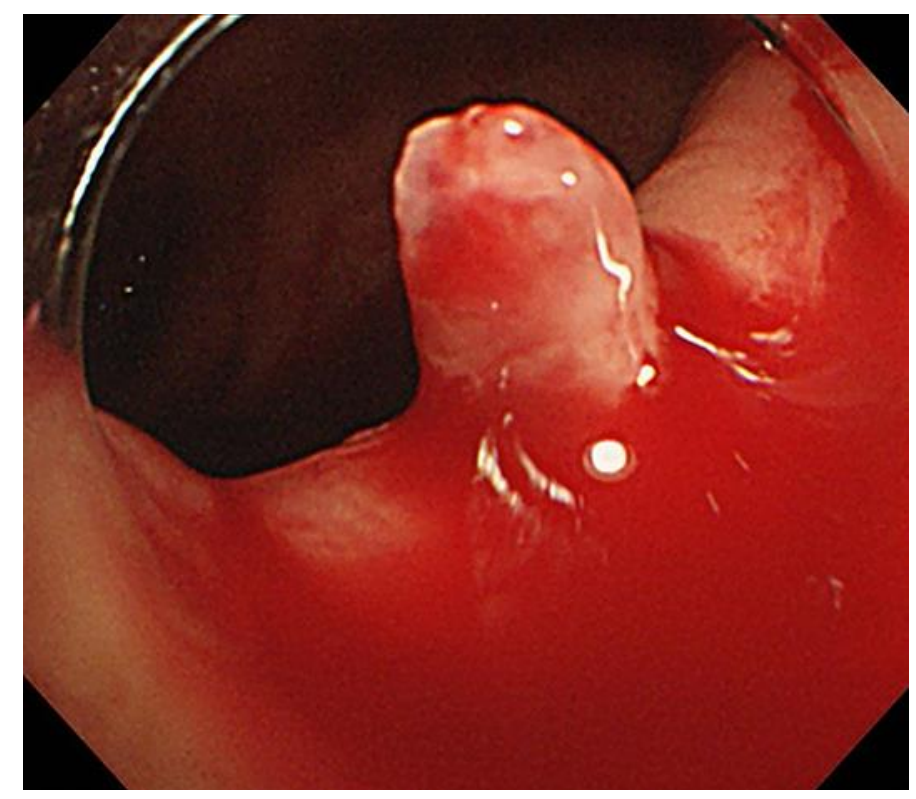

Fig. 2. Photograph showing the exposed blood vessel in the lower rectum during colonoscopy. 